\title{
Minining
}

\section{Potvin stability graph applied to brazilian geomechanic environment}

\section{Gráfico de estabilidade aplicado ao contexto geomecânico brasileiro}

http://dx.doi.org/10.1590/0370-44672014670171

\section{Michel Melo}

CEFET -MG - DEMIN

Araxá - Minas Gerais - Brazil

michelmelo@gmail.com

\section{Cláudio Lúcio Lopes Pinto \\ Universidade Federal de Minas Gerais - \\ Departamento de Engenharia de Minas \\ Belo Horizonte - Minas Gerais - Brazil \\ cpinto@demin.ufmg.br}

José Ildefonso Gusmão Dutra.

Universidade Federal de Minas Gerais -

Departamento de Engenharia de Minas

Belo Horizonte - Minas Gerais - Brazil

jidutra@demin.ufmg.br

\begin{abstract}
Empirical methods should be restricted to situations similar to the circumstances used for their development. The Stability Graph Method, first proposed by Mathews et al. (1981) and later modified by Potvin (1988), was based on data from Canadian and Australian mines. Therefore, there is no evidence of their use in the Brazilian geomechanical context. The Stability Graph Method is intended to design a stable open stope in mines using the Sublevel Stoping Mining method. The present study investigates the applicability of the methods in Sublevel Stoping Brazilian mines. This is a contribution to the validation of the use of the methods in the Brazilian geomechanical context.
\end{abstract}

Keywords: : stability graph, overbreak, open stope.

\section{Resumo}

Qualquer método empírico tem sua aplicabilidade restrita a situações onde há semelhanças com os dados utilizados para sua elaboração. O Método do Gráfico de Estabilidade, proposto primeiramente por Mathews et al. (1981) e posteriormente modificado por Potvin (1988), foi desenvolvido a partir de dados relativos a minas canadenses e australianas. O Método do Gráfico de Estabilidade tem a finalidade de estimar as dimensões para um realce estável em minas que utilizam o Método de Lavra Sublevel Stoping. Portanto não há evidências de que sua utilização, no contexto geomecânico brasileiro, permita uma boa estimativa das dimensões do realce. O presente trabalho buscou evidências para aplicação dos métodos em minas de Sublevel Stoping brasileiras. Esta é uma contribuição para a validação da utilização do método no contexto geomecânico brasileiro.

Palavras-chave: gráfico de estabilidade, diluição, realces.

\section{Introduction}

The open stope stability can be estimated by its operational dilution. This variable distinguishes the planned stope from the actual excavated stope. Dilution decreases the stope's average grade and affects the mine production rate.

Aiming for higher productivity and to increase the knowledge on open stopes, Mathews el al. (1981) proposed the Stability Graph Method based on
26 case studies of three Canadian and Australian mines. Contributions were made by Potvin (1988), Palkanis (1986) and Mawdesley et al. (2001).

The Stability Graph Method employs a chart where the stability number is plotted in the y axis and the hydraulic radius in the $\mathrm{x}$ axis. The stability number is a modification of Barton's et al. (1974) NGI- Q rock mass classifica- tion. Kaiser et al. (1986) suggest that the SRF coefficient is conservative as it was conceived to be applied in civil constructions. Three new factors were created in replacement of the SRF coefficient: The A factor related to the stress field; the $\mathrm{B}$ factor that refers to the most critical joint; and the $\mathrm{C}$ factor taking into account the gravity effects. Povin's Stability Number can be expressed by: 
$N^{\prime}=\left(\frac{R Q D}{J_{n}}\right)\left(\frac{J_{r}}{J_{a}}\right) \times A \times B \times C$

Here, $N^{\prime}$ is the Stability Number, $A$ refers to the rock stress factor, $B$ accounts for the joint orientation adjustment and $C$ represents the gravity adjustment.

The hydraulic radius (H.R.) is largely used for several engineering purposes (Potvin, 1988). In this instance, it is defined mathematically by the ratio between stope surface area and stope surface perimeter.

A database comprising 175 case studies from 34 mines were used in the Potvin (1988) proposition. One of the

\section{Materials and methods}

Mathews et al. (1981) and Potvin (1988) methodologies have been efficiently applied on Australian and Canadian mines.

The use of Potvin's (1988) methodology in Brazilian mines requires on site data collection and, possibly, a new Stability Graph to be compare to the proposed ones.

The data collected can be summarized as:

- Stope dimensions and geological ambient.

- Estimated in-situ and induced stress fields.

- Rock mass classification in stope area.

- Relative position of joint and stope surfaces.

- Rock mass strength.

- Mined stopes dilution.

- Use of support to verify stability with or without these systems.

The data used in this study was not obtained with the main purpose of the Stability Graph analyses. Thus, some re- differences between his methodology and Mathews original proposal is the absence of Jw factor. This absence was not clearly explained by Potvin. One could guess that the water pressure is already taking care of in numerical modelling to obtain induced stresses. The factors $A, B$ and $C$ have the same meaning as for Mathews et al. (1981) but attain new values due to the use of a larger database.

Mathews et al (1981) propose the maximum of $10 \%$ of operational dilution sults might have been tainted by the data gathering process. Structural mapping and geomechanic classification for each particular stope site should be considered, both, before and after excavation. That would allow more accurate quantification

Two Sublevel Stoping mines were used to gather the database. Seventeen stopes provided the data of the topographic surface - laser scanning, critical joints orientations, in-situ stress field and NGI-Q rock mass classification.

The dilution was estimated by discretizing solids (planned and realized stopes) in a mine planning software. A Boolean operation allowed obtaining the dilution of each stope and for each stope surface. The same software was used to access the surfaces areas and hydraulic radius.

Potvin's (1988) A factor is defined by the ratio of the uniaxial compressive strength and the highest total stress at the stope surface. The uniaxial compressive strength was provided by the mines, of blasting effects. for considering an open stope as stable. Meanwhile Potvin (1988) proposes 5\%. This difference stresses the necessity of a judicious choice of which methodologies to be used. Operating dilution estimations are discussed by Oliveira et al. (2012).

Potvin's methodology was chosen since the larger database used by the author allowed the best adjustments to the original site conditions. Suorimeni (2010) discusses the possibility of a unique Stability Graph comprising all studies reported. via internal report. The induced stresses were estimated using numerical modelling (Rocscience Phases 25.0 and Examine 3d Free Trial).

The orientation of the critical discontinuity relative to the stope surfaces is used to obtain Potvin's (1988) B factor. All stopes and structures were georeferenced so that their orientation could be estimated by by simple geometry. In this research, the rocscience dips 5.1 was used to access this information.

The average dipping angle of each stope surface was used to find the $\mathrm{C}$ factor. Field and data observations show that gravity contributes only to free rock falls. There are no sliding blocks at the analyzed stopes.

The obtained results were plotted on a graph where the $\mathrm{x}$ axis is defined by the hydraulic radius and the $y$ axis by the stability number. Potvin's (1988) stability limits were presented in graphs. Therefore, after the analysis, each surface was identified as stable, potentially unstable or caving.

\section{Results}

\section{Rock mass classification}

All the analyzed stopes would fall into one of three different geomechanical domains. Table I shows all rock mass classification parameters for each domain. The mines provided all information in this table. Q', the modified rock mass

\begin{tabular}{|c|c|c|c|}
\hline \multicolumn{4}{|c|}{ Rock Mass Classification } \\
\hline & Domain 1 & Domain 2 & Domain 3 \\
\hline RQD & 80.00 & 70.00 & 90.00 \\
\hline$J_{n}$ & 15.00 & 9.00 & 9.00 \\
\hline$J_{a}$ & 1.00 & 1.50 & 1.50 \\
\hline$J_{r}$ & 6.00 & 2.00 & 1.00 \\
\hline $\mathrm{Q}^{\prime}$ & 0.89 & 5.83 & 15.00 \\
\hline
\end{tabular}

(1) 


\section{A Factor determination}

The rock strength (U.C.S) of each domain was estimated by uniaxial compressive strength tests carried out

Table II

Uniaxial Compressive Strength by domain.

All the stopes, located less than 400 meters deep, were numerically modelled in Phases 2 and Examine 3d. The 3d modelling was used to estimate the field stress at the stope end and stope beginning and where there were interactions

Table III

Factor A of all surfaces on Stope 1.

\section{$B$ Factor determination}

Table IV presents the considered critical joints attitude in all three domains.

Table IV Critical Joints Attitudes.

Two joints were initially considered in the first domain. The angular position was then calculated for both and the one that more significantly influenced the instability was chosen to estimate

Table V B factor for all surfaces of Stope 1.

\section{Factor determination}

Only rock falls were considered as the gravity contribution on instability. Due to the stopes complex geometry, their by the mines, according to the International Society of Rock Mechanics (ISRM) suggestions.
Table II presents the average values and the numbers of test accomplished.

\begin{tabular}{ccc}
\hline \multicolumn{3}{c}{ Uniaxial Compressive Strength U.C.S } \\
\hline & U.C.S (MPa) & Number of Tests \\
\hline Domain 1 & 175.5 & 13 \\
Domain 2 & 118.0 & 9 \\
Domain 3 & 98.8 & 5 \\
\hline
\end{tabular}

with other excavations. The supported stopes were modelled through a two dimensional analysis. The $3 \mathrm{~d}$ analysis helped the interpretation of the two dimensional results.

The shallow depth combined with the high rock resistance $(+98 \mathrm{MPa})$ deemed the ratio of U.C.S to induced stress never smaller than 2 and, consequently, the A Factor equals 1.

As an example, Table III shows the A factor for all surfaces of Stope 1.

\begin{tabular}{lcc}
\hline Stope & Surface & A Factor \\
\hline & Roof & 1 \\
\cline { 2 - 3 } Stope 1 & Stope Beginning & 1 \\
\cline { 2 - 3 } & Stope End & 1 \\
\cline { 2 - 3 } & Hangingwall & 1 \\
\cline { 2 - 3 } & Footwall & 1 \\
\hline
\end{tabular}

This information was provided by the mines. It is relevant to notice that these joints are critical only to the roofs and hangingwalls.

It is supported by observations of local mining engineers.

\begin{tabular}{lcc}
\hline & Critical Joint Attitudes by Domain & \\
\hline & Dip Direction & Dip \\
\hline Domain 1 & 141 & 64 \\
Domain 1 & 313 & 54 \\
Domain 2 & 245 & 45 \\
Domain 3 & 238 & 43 \\
\hline
\end{tabular}

the $\mathrm{B}$ factor.

Table V shows the spatial orientation of the Stope 1 surfaces. All analyzed roofs were horizontal and in Domain 1, rendering the same $B$ factor. The same happened with the stope end and stope beginning surfaces. Both are vertical and included in Domain 1. All footwalls came up with the $B$ factor equals to 1 , probably due to a structural mapping bias.

\begin{tabular}{cccc}
\hline Stope & Surface & Critical Joint Attitude & Angle \\
\hline & Roof & $54 / 313$ & 54.00 \\
\cline { 2 - 4 } & Stope Beginning & $64 / 141$ & 65.92 \\
\cline { 2 - 4 } Stope 1 & Stope End & $64 / 142$ & 65.92 \\
\cline { 2 - 4 } & Hangingwall & $64 / 143$ & 39.61 \\
\cline { 2 - 4 } & Footwall & $54 / 313$ & 29.02 \\
\hline
\end{tabular}

transversal sections vary considerably. As a solution for this problem, a segment line was constructed from the roof to the floor on the hangingwall and on the footwall surfaces. The angle used on the $\mathrm{C}$ Factor estimation was the average of all the seg- 
ment angles in all transversal sections. Here the roof and floor were considered

horizontal again.

The average inclinations of stope

\begin{tabular}{cccc}
\hline Stope & Surface & Avg. Inclination & C Factor \\
\hline \multirow{3}{*}{ Stope 1 } & Roof & 0 & 1.00 \\
\cline { 2 - 4 } & Stope Beginning & 90 & 8.00 \\
\cline { 2 - 4 } & Stope End & 90 & 8.00 \\
\cline { 2 - 4 } & Hangingwall & 78 & 6.54 \\
\cline { 2 - 4 } & Footwall & 102 & 8.00 \\
\hline
\end{tabular}

\section{Determining the Potvin (1988) N' Stability Number}

The stability number proposed by I) and the factors A, B and C discussed Potvin (1988) is obtained by multiplying the earlier. (Equation 2). Table VII presents modified rock mass classification Q' (Table the stability number reckoned for Stope 1.

\begin{tabular}{ccc}
\hline Stope & Surface & N' Potvin \\
\hline & Roof & 0.88 \\
\cline { 2 - 3 } Stope 1 & Stope Beginning & 3.18 \\
\cline { 2 - 3 } & Stope End & 3.18 \\
\cline { 2 - 3 } & Hangingwall & 2.57 \\
\cline { 2 - 3 } & Footwall & 7.04 \\
\hline
\end{tabular}

\section{Dilution determination}

Dilution calculation using block models presented satisfactory results (further discussion in Oliveira et al. (2012)). The hangingwalls, on most

\section{Hydraulic radius determination}

The hydraulic radius was calculated using the proposed formulation.

A similar hydraulic radius was

\section{The Stability Graph}

Seventeen stopes of two different mines, 10 from the first and 7 from the second, were used in this study.

The variables of interest for a total of 65 surfaces (hangingwall, footwall, roof, stope end, stope beginning) were of the stopes, were responsible for the higher dilutions.

Nevertheless the dilutions in some footwalls reached up to $16.92 \%$.

estimated for all the roofs .

The same circumstances were observed for all footwalls

either measured or estimated; namely: hydraulic radius, stability number and dilution.

Figure 1 shows the Stability Graph with the limits defined by Potvin (1988). Potvin and Hagjigeorgiou (2001) clas- surfaces and calculated C factors are presented in Table VI.

Table VI

Calculated Factors C for Stope 1.
Table VII

Potvin(1988) stability number for all stope surfaces of stope 1.

Two stopes presented footwall dilutions higher than on hangingwalls.

It might be due to biased footwall analysis.

and hangingwalls.

This can be explained by the similarity of the form of such surfaces.

sified these limits as: stable surface for dilutions lower than $5 \%$, potentially unstable for dilution ranging from $5 \%$ to $10 \%$ and caving when the dilution reaches values higher than $10 \%$.

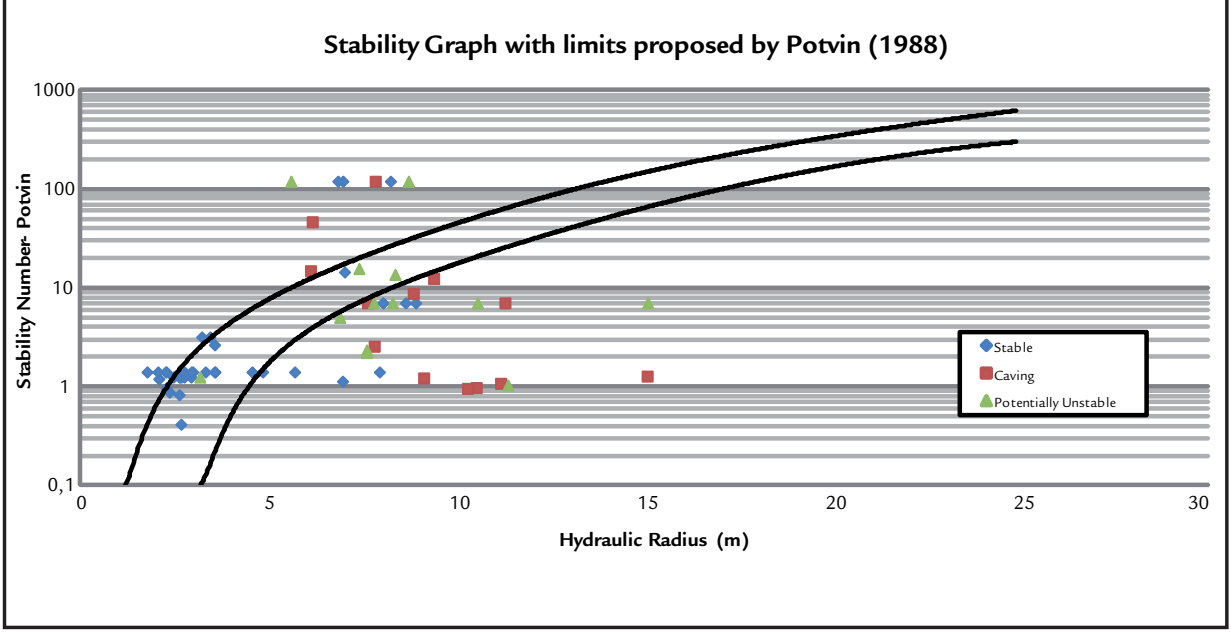

Figure 1

Stability Graph with Limits proposed by Potvin (1988) 
It can be seen in the graph depicted in Figure 1 that most of the points representing the surfaces analyzed do not agree with the limits proposed by Potvin (1988).

Also, observe that there is a distinct group of surfaces considered stable, some proximity of the points that represent unstable surfaces and a greater dispersion of the surfaces considered potentially unstable.

Figure 2

Stability Graph with Limits proposed by Potvin (1988), just hangingwalls and roofs considered.

Supports were used in all roofs analyzed, circled in red in the graph of Figure 2. The low dilution responsible for their classification as stable surfaces was probably influenced by the use of these supports.

Observing only the hangingwalls points, all those considered stable, circled in blue, (dilution $<5 \%$ for Potvin and Hagjigeorgiou (2001)) are not in the stability zone proposed by researchers.

Figure 3

Extended Stability Graph considering only hangingwall and roofs.

A further analysis was accomplished using Mawdesley et al. (2001) charts con-
Other aspects of the graph should be highlighted:

1) All footwalls, stope ends and stope beginnings might show inaccuracies in determining the number of stability due to simplifications on modelling these surfaces,

2) the small number of points or surfaces analyzed (65) did not allow a wider distribution of the points on the graph,
3) the shallow depth (400 meters at most) of the observed stopes resulted in an equality of the A factor for all the excavations surfaces, and

4) the use of support on some surfaces might have enhanced the stability of such excavations.

To investigate the bias associated to these results, a new graph was plotted containing only hangingwalls and roofs. This graph can be seen on Figure 2 .

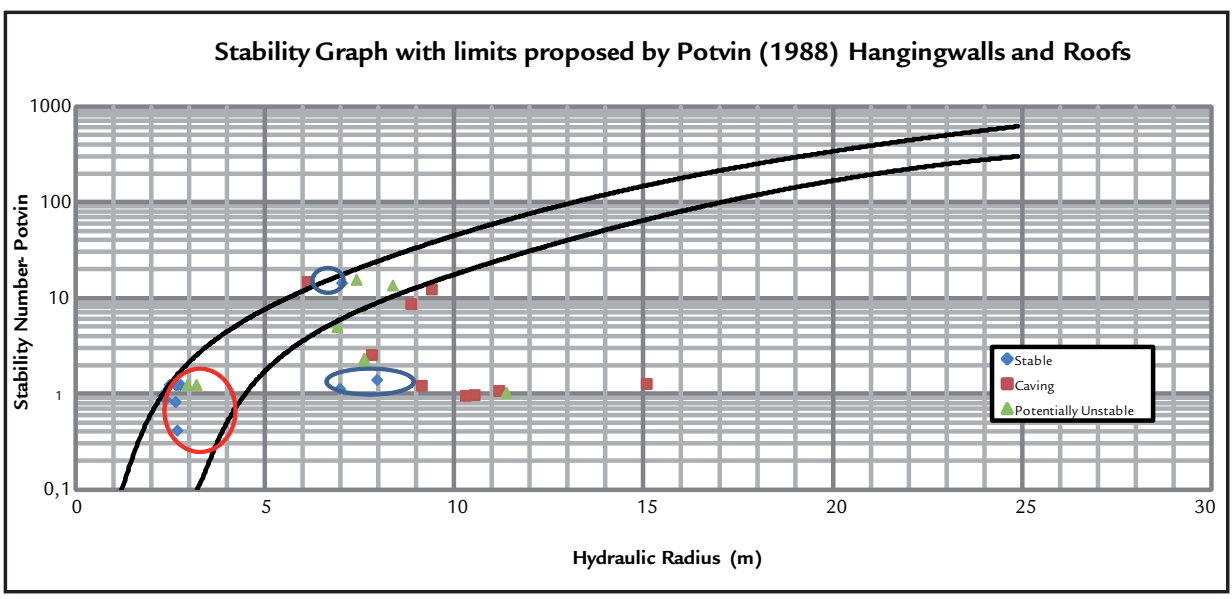

A greater number of surfaces would be necessary to allow a more objective statistical analysis. Meanwhile, another graph based on probabilistic analysis proposed by Mawdesley et al. (2001) was devised and presented in Figure 3, even though it was originally proposed to be based on Mathews et. al. (1981)'s considerations.

Again only hangingwalls and roofs were considered.
According to his original chart, in the area above the superior line, there would be found $83 \%$ of stable surfaces and $17 \%$ potentially unstable surfaces. Under the inferior line, 60\% of the surfaces were stable, $27 \%$ potentially unstable and only $13 \%$ resulted in caving.

The data collect at the two mines do not agree with the limits proposed by Mawdesley et al. (2001).

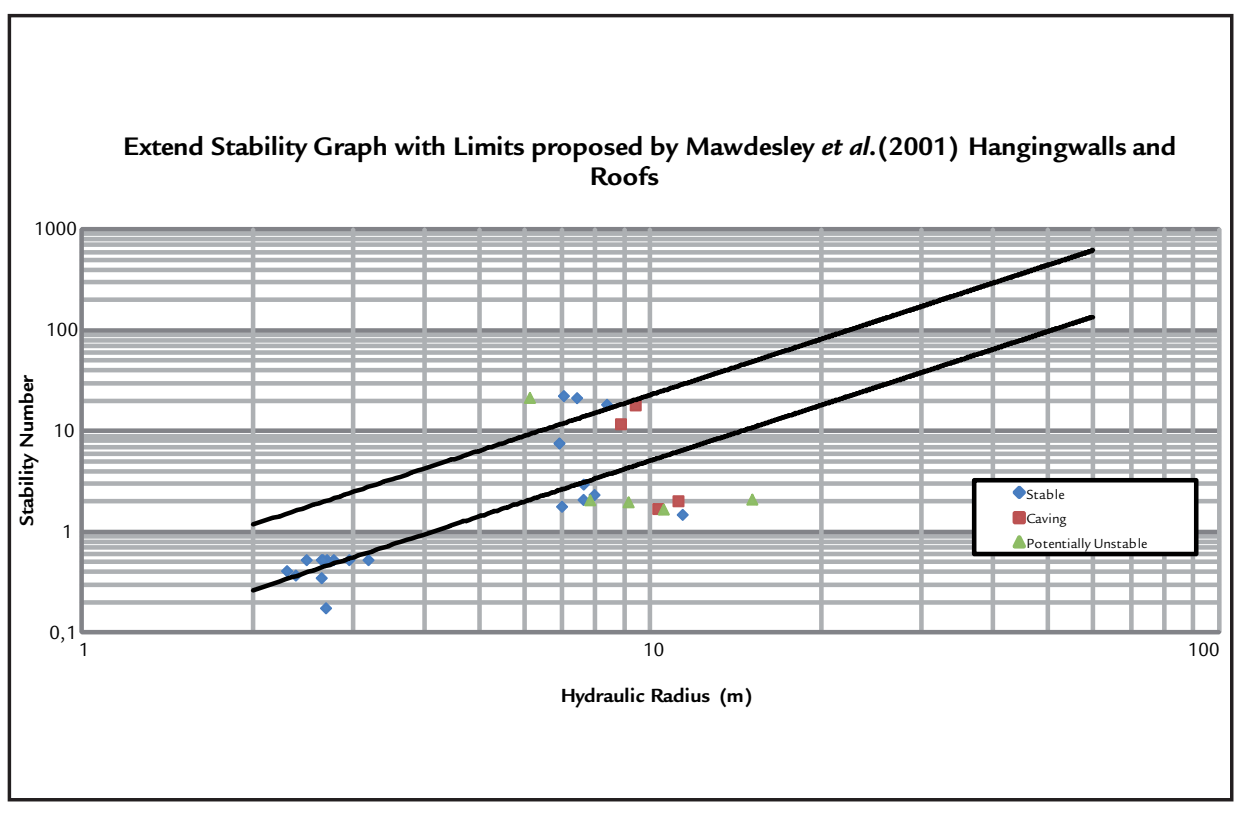

sidering isoprobability lines of stability. The graph can be seen in Figure 4. 


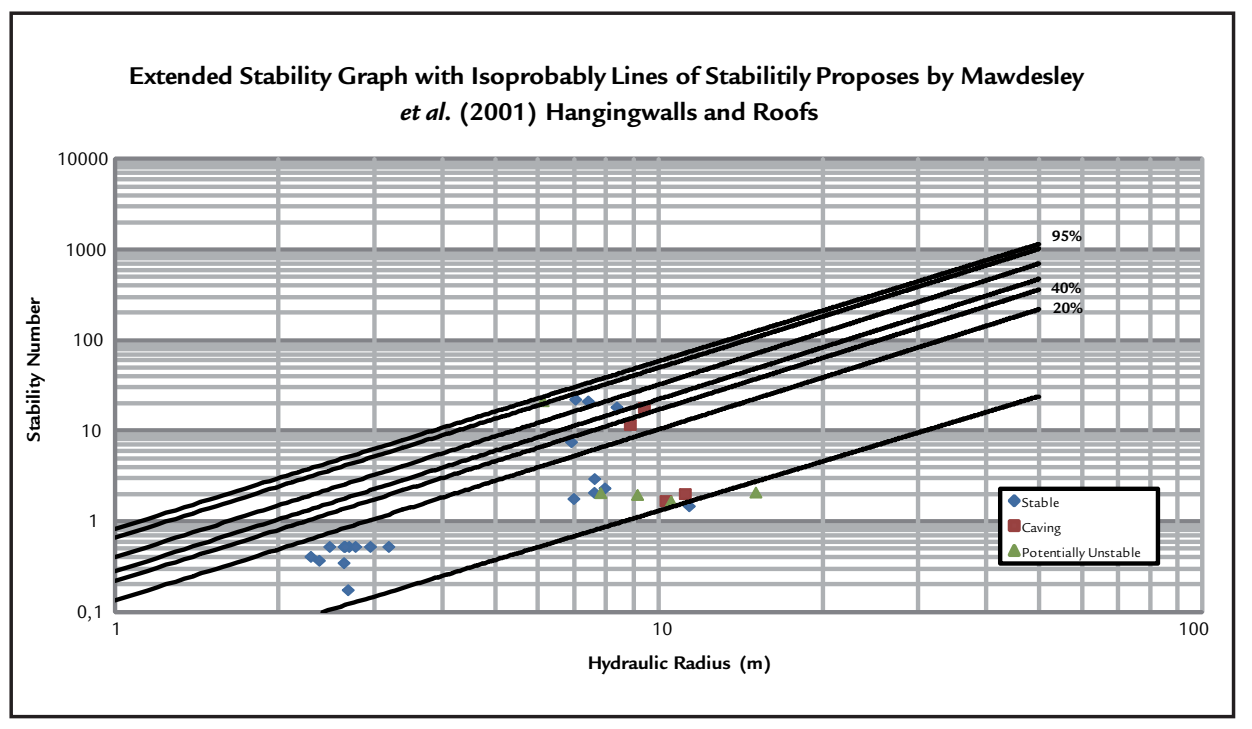

It can be noticed that, disregarding the roofs, only one point disagrees with the isoprobability lines proposed. This surface shows a dilution of $5.74 \%$, considerably close to the stable limit proposed by Potvin (1988). The Mawdesley et al.

\section{Conclusions}

A general geomechanics classification of a mine site could induce to errors in the empirical model interpretation. It seems that footwalls have been ignored in analysis to define critical discontinuities used to estimate the Factor $B$. There were instances where the footwall presented higher operational dilutions, but conservative $B$ Factor values.

The chances of slipping and/or falling blocks must be analyzed accurately for each stope face. Analyses of the $C$ Factor for footwalls, stope beginnings and stope ends has proven to be inef-

\section{Bibliographic references}

(2001) iso-probability instability limits also show a good concordance with the cases analyzed.

The limited data bearing just on clear inconsistent results might not be taken as a solid indication that the this ficient. It could be related to the widespread assumption at the mines that, in all surfaces, the gravity falling blocks was the unique failure mechanism to be considered. That resulted in the definition of a single value for the $C$ Factor for all surfaces analyzed.

The number of case studies directly influences the quality of the result of an empirical model. In this paper, the number was not sufficient to propose modifications to the limits of stability proposed by Potvin (1988). The fact that only two companies contributed to the
Figure 4

Extend Stability Graph with isoprobability lines of stability, considering hangingwalls and roofs alone.

procedure could be used by the mines studied, neither would it be possible to propose other limits of (in)stability. Nevertheless, it suggests that new cases should be analyzed in the construction of a more robust database. study also showed a trend of stability enhancements open to Brazilian mines.

The extended stability graph proposed by Mawdesley et al. (2001) reveals the highest number of cases studied. Even though, it is based on Mathews et. al (1981)'s suggestion, it presented a better correlation between the isoprobability lines and the hangingwall and roof data. A single point (hangingwall) showed disagreement with the authors' proposal, indicating a situation of stability below the line that represents the probability of $0 \%$ stable surfaces.

BARTON, N., LIEN, R., LUNDE, J.. Engineering classification of rock masses for the design of tunnel support. Rock Mechanics. v.6, n.4, p. 189-236, 1974.

KAISER, P.K., MACKAY, C., GALE, A.D.. Evaluation of rock classifications at B.C. Rail Tumbler Ridge Tunnels. Rock Mechanics and Rock Engineering. New York, v.19 p. 205-234, 1986.

MATHEWS, K. E., HOEK, E., WYLIE, D.C., STEWART, S.B.V. 1981. Prediction of stable excavation spans for mining at depths below $1,000 \mathrm{~m}$ in hard rock mines. Canmet Report DSS Serial No. OSQ80-00081, 1981.

MAWDESLEY, C., TRUEMAN, R., WHITEN, W.. Extending the Mathews stability graph for open- stope design, Trans. IMM (Sect. A: Min. industry), n.110 A27-39, 2001.

OLIVEIRA, M.M., PINTO, C.L.L., DUTRA, J.I.G., DIAS, P.M..Utilização de modelo de blocos para o cálculo do overbreak (diluição operacional) e determinação da estabilidade das superfícies do realce para calibração do método do Gráfico de Estabilidade, CONGRESSO DE MINA SUBTERRÂNEA, n.7 BELO HORIZONTE, 2012.

PAKALNIS, R.C. Empirical stope design at Ruttan Mine, Vancouver, Canada: Uni- 
versity of British Columbia Department of Mining and Minerals Processing, 1986.

POTVIN, Y. 1988. Empirical open stope design in Canada. The University of British Columbia, 1998. p.350. (Ph.D. Thesis).

SUORINEMI, F.T. 2010. The stability graph after three decades in use: Experiences and the way forward. International Journal of Mining, Reclamation and Environment, v. 24, n. 4, p. 307-339, 2010.

Received: 12 September 2014 - Accepted: 3 October 2014. 